\title{
La identidad en el plato. El camino identitario argentino a través de sus alimentos
}

\author{
The identity on the plate. \\ The Argentine identity path through its food
}

\author{
ILARIa Magnani \\ i.magnani@unicas.it \\ Università degli Studi di Casino e del \\ Lazio Meridionale
}

\begin{abstract}
Resumen: Junto a la fundamental función material que desempeña, es bien conocido el valor simbólico de la alimentación, capaz de albergar significados culturales, afectivos, identitarios -ya sea a nivel personal que nacional-. Enfatizan estos temas y sus implicaciones históricas estudiosos como Montanari y Flandrin entre otros. Basándome en dichas consideraciones, me propongo rastrear la descripción de las tradiciones alimentarias argentinas para delinear su representación en relación con la naciente identidad nacional, observar sus modificaciones y analizar los significados que ellas entrañan. A este fin me basaré en un corpus formado por: José Antonio Wilde, Buenos Aires desde setenta años atrás (1881); Domingo Faustino Sarmiento, Recuerdos de provincia (1850); Lucio Mansillas, Mis memorias (1904) y Una excursión a los indios ranqueles (1870).
\end{abstract}

Palabras clave: gastronomía, literatura argentina siglo XIX, José Antonio Wilde, Domingo Faustino Sarmiento, Lucio Victorio Mansillas.

Abstract: Along with the fundamental material function that it performs, the symbolic value of food is well known, capable of harboring cultural, affective, and identity meanings -either at a personal or a national level-. These themes and their historical implications are emphasized by scholars such as Montanari and Flandrin, among others. Based on these considerations, I propose to trace the description of Argentine food traditions to delineate their representation in relation to the nascent national identity, observe their modifications and analyze the meanings that they entail. To this end I will base myself on a corpus made up of: José Antonio Wilde, Buenos Aires desde setenta años atrás (1881); Domingo Faustino Sarmiento, Recuerdos de provincia (1850); Lucio Mansillas, Mis memorias (1904) y Una excursión a los indios ranqueles (1870).

Keywords: gastronomy, 19th century Argentine literature, José Antonio Wilde, Domingo Faustino Sarmiento, Lucio Victorio Mansillas. 


\section{La comida. Función y representación}

Por las prácticas selectivas en las que se basa y los valores simbólicos que lo caracterizan «il cibo si configura come elemento decisivo dell'identità umana e come uno dei più efficaci strumenti per comunicarla» afirma el historiador Massimo Montanari (2006: XII). La elaboración de los alimentos y su uso actúan «come segno di appartenenza a una comunità» (Montanari 2021: 12) y el lenguaje de la comida se puede considerar «come fatto in sé stesso politico, giacché le forme di comunicazione non si limitano a esprimere il reale, ma contribuiscono a crearlo» (Montanari 2021: 13) declara el historiador al presentar su más reciente interpretación sobre el tema. Por otra parte el mismo autor nos recuerda que la cocina, lejos de ubicarse en estrecha relación y continuidad con el ambiente natural y sus productos, se centra en la capacidad humana de modificarlos con procesos que alteran su naturaleza (Montanari 2006, 36). Las formas de selección y «alteración» - a partir de la cocción- están en la base de las distintas tradiciones gastronómicas. Estas sufren variaciones a lo largo del espacio y del tiempo además de estar estrechamente vinculadas a las jerarquizaciones sociales y económicas presentes en todo núcleo humano históricamente definido.

Para poder apreciar el valor simbólico de los alimentos, resulta igualmente importante poner atención en las causas que concurren a crear las preferencias alimentares y la «estructura del gusto» -como la denomina Jean Luis Flandrin- de un contexto geográfico, histórico y social. En palabras del mismo Flandrin:

La question est finalement de savoir dans quelle mesure le goût d'un peuple a été modelé par ses pratiques alimentaires traditionnelles - elles-mêmes tributaires de contraintes diverses - et dans quelle mesure au contraire pratiques et goûts se sont opposés. En outre, lorsqu'une transformation des pratiques est attestée, il importe d’établir si le goût l'a suscitée, l'a suivie, ou s'y est opposé? (Flandrin 1983: 370).

A partir de dichos conceptos, el presente trabajo se propone rastrear la descripción de los usos alimentarios argentinos decimonónicos para delinear su representación en relación con la naciente identidad nacional, observar sus modificaciones y analizar los significados que ellas entrañan. Resaltan particularmente algunos núcleos centrales en la definición identitaria nacional: la rechazada tradición hispánica peninsular, la conflictiva relación con las poblaciones autóctonas, la no menos ambivalente acogida de los inmigrantes y, finalmente, la fascinación por Europa. A este fin elijo un corpus formado por: José Antonio Wilde, Buenos Aires desde setenta años atrás (1881); Domingo Faustino Sarmiento, Recuerdos de provincia (1850); Lucio Mansillas, Mis memorias (1904) y Una excursión a los indios ranqueles (1870).

Con excepción de Mansilla, nacido en la década del 30, los autores considerados pertenecen a la primera década del siglo XIX y lo atraviesan integralmente o casi. Sus textos son entonces el fresco de su siglo y de los cambios que en él tuvieron lugar. Huelga decir que estos autores, perteneciendo todos - de nacimiento o por inserción sucesiva- a las capas más encumbradas de la sociedad de la época, nos proporcionan datos fundamentalmente referidos a estos sectores sociales 
y solo ocasionalmente nos brindan informaciones sobre otros ámbitos con una mirada cargada de toda la distancia social y cultural del caso. De un punto de vista espacial, la mirada se centra en la capital y sus idiosincrasias sin que falten referencias a las zonas del interior, de parte de Sarmiento, así como a las «bárbaras» tradiciones de Tierra Adentro -las extensiones del territorio nacional bajo el control de las poblaciones originarias- de parte de Mansilla.

Todos los textos -aunque de forma distinta- se presentan como memorias personales, biográficas: lindan con lo autobiográfico o conforman una narración que, reuniendo una apreciable cantidad de datos, pretende brindar una imagen fehaciente del pasado. ${ }^{1}$

Cabe considerar, como recuerda Molloy (1988: 408), que dicha forma escrituraria era la privilegiada por los historiadores de la época, aunque el carácter biográfico o autobiográfico de las obras debilitara el valor documental de los textos. No por casualidad, entonces, se aprecia en estas obras un esfuerzo de historización del contexto que otorgue autoridad a los recuerdos haciendo de ellos otros tantos «reflejos» de la Historia. Si bien de forma menos acentuada, los utilizados por todos nuestros autores son los mismos ardides identificados por Molloy en la redacción sarmientina de Mis recuerdos es decir la creación del «tinglado de "documentos" previos que [el autor] arma para justificar la escritura de sí, insertarla ilusoriamente en una cadena escrituraria y de ese modo validarla ante la historia» (Molloy 1988: 409). Estos artificios hacen que la memoria "parienta pobre en el rastreo histórico que se reivindica para el trabajo biográfico, pas[e] a cobrar nueva importancia» se vuelva confiable y «única vía posible en el trabajo de restauración [gracias a una] memoria personal, ampliada por "la memoria de mis deudos"》" (Molloy 1988: 409-410). Si el proceso de ampliación familiar es fundamental, a menudo acompañada de una acusada intertextualidad, una autorización intelectual es igualmente relevante en las obras mencionadas, empezando por el entramado de citas y alusiones presente en Mansilla, donde se vuelve verdadera marca autoral.

\section{Imágenes de las prácticas alimentares porteñas}

Si bien el dato familiar y autobiográfico aflora en varias ocasiones a lo largo de las páginas de José Antonio Wilde ${ }^{3}$ este no lo incluye entre sus finalidades y afirma en el epílogo que objetivo de la

1 Si Wilde se hace cargo de reconstruir etapas históricas de las que solo puede tener escasos recuerdos, ya que habla de la década del 20 habiendo nacido en 1813, los textos de Sarmiento y Mansilla, en cambio, se presentan como memorias personales.

2 Analizando la función del relato familiar en Sarmiento, Molloy (1988: 411) identifica un antecedente autorizado de la narración oral materna en la estructura elegida por El Inca Garcilaso en sus Comentarios, y lo considera un fecundo punto de partida de una genealogía textual sucesiva.

3 José Antonio Wilde (Buenos Aires 1813-Quilmes 1885), tío del más conocido Eduardo, era hijo de un inglés que, comisionado para fundar el banco Oficial, llegó a Buenos Aires a comienzos del siglo XIX. Fue médico de un gran renombre tanto por su dedicación cuanto por su saber. En el campo de la educación tuvo no comunes méritos, distinguiéndose como profesor e inspector de escuelas; fue vocal del primer Consejo Nacional de Educación, 
obra «fue arrancar del olvido ciertos rasgos característicos de nuestro estado social, en una época ya lejana, y por su simple exposición poner en relieve el progreso actual» (2000: 333). El autor declara de esta manera un típico posicionamiento de inspiración positivista, aunque tal vez no coincida integralmente con las observaciones reunidas.

La narración abarca los años que van de 1810 -fecha de los primeros conatos independentistas- a la culminación del largo proceso que llevó a Buenos Aires a convertirse en capital de la República transitando por los enfrentamientos de la etapa rosista y el derrocamiento del dictador. Un arco temporal explícitamente declarado por Wilde, aludido o sobrentendido por los demás.

En la obra de Wilde desfila el Buenos Aires decimonónico: las estaciones de ferrocarril, las escuelas, los teatros, las plaza y las calles con sus vendedores ambulantes, los interiores de las casas y sus decorados; las costumbres y los atuendos; los cafés y los hoteles. Muchas páginas describen los alimentos usados, su venta, la morfología de su elaboración y la sintaxis de su consumo, acudiendo a la comparación con la estructura lingüística propuesta por Montanari (2006: 137-142).

Wilde nos presenta una ciudad atrasada con mercados desorganizados - a veces pura aglomeración de ambulantes con sus carretas reunidas en las calles-, de condiciones higiénicas precarias. ${ }^{4}$ Otros

del cual era presidente Sarmiento. Cuando se graduó se instaló en el pueblo de Quilmes, donde fue miembro de la municipalidad. Allí fundó, en 1873, el primer periódico que se publicó en la zona: El Progreso de Quilmes donde desarrolló una no desdeñable actividad periodística. En 1884 asumió la dirección de la Biblioteca Nacional. Fue autor de libros destinados a la escuela y de textos de medicina.

4 «El modo de vender carne fue por muchos años, entre nosotros, repugnante por mil circunstancias, y muy especialmente por falta de aseo. A ciertas horas de la mañana y de la tarde, se estacionaban en diversos puntos, principalmente en las bocacalles, unas carretillas con toldos y costados de cuero vacuno o caballar, en que venía la carne colgada en ganchos. Llegados allí desprendían los caballos, quedando la carreta inclinada hacia adelante, descansando sobre el pértigo; frente a éste, extendía el carnicero sobre el suelo (con barro o con polvo), un cuero en el que destrozaba la carne con hacha, pues que entonces nadie soñaba en dividir los huesos con serrucho. El cuero presentaba centenares de soluciones de continuidad, por las que pasaba a la carne o el barro o el polvo. Es claro que el carnicero no lo mudaba sino cuando ya estaba hecho triza e inservible. Cuando llegaba la noche, raro era el que ostentaba un farol; casi siempre encendían una vela de sebo (vela de baño), hacían una incisión en un cuarto de carne y allí colocaban la vela, que con la brisa o el viento fuerte, según fuese el caso, goteaba o chorreaba el sebo sobre la carne, que era un gusto. Como el despacho se hacía inmediato al cordón de la vereda, el viandante no dejaba de pasar con cierto recelo, al ver enarbolar la enorme hacha: ni se veía libre de algunos salpiques.

Esta carne, tan desaseadamente conducida, tan desaseadamente despachada, iba a dar a la tipa no menos desaseada, de la negra cocinera que era la compradora. Esas tipas eran de cuero, y cuando más de junco con fondo de cuero, de las que construían los negros; poco se conocía la canasta de mimbre. Aquellas tipas, por mucho que se quisiesen cuidar, siempre ofrecían una vista desagradable y un aspecto repugnante, repugnancia que sólo la costumbre podía atenuar un tanto. El traje del vendedor o carnicero estaba en relación; calzoncillos anchos con fleco, y en los más lujosos con cribo, salpicado de sangre y de lodo; en mangas de camisa en verano, con poncho en invierno, descalzo o con bota de potro. El modo desaseado de conducir la carne desde los mataderos sobrevivió por muchos años a la abolición de las carretillas, pues hasta hace poco se traía en carros y aun a caballo, expuesta al sol, el polvo, el lodo, etc. Es de data muy reciente su condución en carros aseados, con cortinas y demás accesorios. Cruzaba también por nuestras calles 
productos, como leche, pan y agua, -nos cuenta el autor- eran repartidos a domicilio, mientras algunas comidas se vendían, ya preparadas, en la calle como pescado frito, pasteles, tortas o mazamorra.

Si se omiten los pocos hoteles que servían «a la inglesa» (Wilde 2000: 196), la condición de fondas y bodegones resulta igualmente lamentable: «todo era sucio, muchas veces asqueroso; manteles rotos, grasientos y teñidos con vino carlón, cubiertos ordinarios y por demás desaseados» (Wilde 2000: 197). Pero, dejemos la sintaxis y pasemos a la morfología -el menú- que, en palabras de Wilde:

se limitaba, generalmente [...] a lo que llamaban comida a uso del país; sopa, puchero, carbonada con zapallo, asado, guisos de carnero, porotos, de mondongo, albóndigas, bacalao, ensalada de lechuga y poca cosa más; postre, orejones, carne de membrillo, pasas y nueces, queso (siempre del país), y ése de inferior calidad» (Wilde 2000: 197).

La comida doméstica, aun siendo un poco más variada, muestra una sustancial homogeneidad con la anterior. El autor proporciona una detallada

lista de los platos que más se servían en nuestras mesas: [...]. Sopa de arroz, de fideos, de pan y de fariña; puchero, desde el caldo limpio hasta la olla podrida. Asado de vaca, carnero, cordero, ave, matambre; la carne de ternera poco o nada se empleaba en la cocina del país. Guisos de carne, carbonada con zapallo, papas o choclos; picadillo con pasas de uva, albóndiga con ídem, zapallitos rellenos y estofado con ídem; niños envueltos, tortilla (pésimamente hecha con harina); guisos de porotos, lentejas, chicharos, etc.; ensaladas de chauchas con zapallitos, lechuga, verdolaga, papas, coliflor y remolacha; locro de trigo o de maíz, humita en grano o en chala, y algunos extraordinarios, carne con cuero, etc. Postre, mazamorra, cuajada, natilla, bocadillos de papa o batata, dulce de todas clases en invierno y fruta de toda clase en verano. (Wilde 2000: 216)

Las costumbres domésticas, por otra parte, resultan ser tan rudimentarias como las de los bodegones:

La pieza en que se comía era por lo general espaciosa, y lo parecía tanto más por lo despojada que se encontraba. [...] La mesa, cubierta con un mantel de algodón [...], no contenía ni bandeja para pan, ni cuchillo de balanza, ni salseras, ni ensaladeras, ni mostaceras, ni lujosas salvillas, ni tanto otro apéndice que hoy se hace indispensable en nuestras mesas. Había un número suficiente de platos; el vino [...] se ponía a la mesa en botella negra, y se tomaba en vaso, porque hasta hace algunos años, nadie tomaba vino en copa; una jarra con agua y eso creemos era todo. En las casas menos acomodadas, pero no tan absolutamente pobres que no pudiesen tener más, sino

\footnotetext{
el carnero con una pila sobre el caballo, de cuartos de carne de oveja, que colgaban por ambos contados, atravesando pantanos y recibiendo sus correspondientes salpiques de barro.

Después de las carretas en las calles, vinieron los puestos o cuartos de carne en diversas partes de la ciudad. Esto duró mientras no se establecieron los mercados y con ellos los radios. Entonces poco a poco fuese introduciendo el traje más decente de los vendedores, las mesas de mármol y demás mejoran que hoy todos conocen. Emprendiéronse también importantes reformas en los mataderos» (Wilde 2000, 288-290).
} 
porque era la costumbre, se servía el vino para todos en un solo vaso, o en dos cuanto más; vaso que pasaba de mano en mano y por consiguiente de boca en boca de los presentes (Wilde 2000: 215-216). ${ }^{5}$

Volviendo a los alimentos, podemos ver como en ambos casos prima la carne, sobre todo la de vaca, cocinada con preparaciones que van de lo hervido a lo asado pasando por los guisos; también se aprecian las marcas de una gastronomía híbrida, mezcla de platos de la tradición peninsular con otros típicamente americanos como carbonada, ${ }^{6}$ locro, ${ }^{7}$ humitas, ${ }^{8}$ mazamorra. ${ }^{9}$ Los vegetales son pocos, representados por lo general por las legumbres.

Me interesa ahora referirme a la narración de Mansilla. ${ }^{10}$ Empecemos con decir que Mis recuerdos ${ }^{11}$

5En su descripción de los simples platos elaborados en la época y su escueta presentación, Wilde los connota como la contracara de cierta tradición difundida en las cortes renacentistas europeas, la llamada «tavola da guardare» (Campanini 2021: 42).

6Es un plato típico del noroeste de Argentina, Chile y Bolivia. En su versión tradicional es realizado sobre un fogón de leña con trozos de zapallo, maíz blando, carne (preferentemente de ternera), batatas o papas y duraznos secos. Se hierve hasta que el caldo y los ingredientes obtengan una consistencia bastante espesa, hecho que le diferencia de un puchero. La denominación parece derivar del hecho de que este guiso se cocina hasta que todos los leños del fogón quedan totalmente carbonizados.

7El locro es un plato elaborado a base de maíz blanco, porotos, zapallo o calabaza y varios tipos de carne. Su cocción prolongada permite utilizar cortes de carne duros y admite diferentes versiones variando los ingredientes. Tiene su origen en la época de la conquista española de América y refleja la fusión de las dos culturas. Por su historia y lo que representa se convirtió en una comida típica de las fechas patrias de Argentina.

8 La humita -nombre de derivación quechua- es una comida basada en el maíz que se consume en el área andina. Consiste básicamente en una pasta o masa de maíz levemente aliñada, envuelta y finalmente cocida o tostada en las propias hojas de una mazorca de maíz.

9 La mazamorra es un postre popular de varios países latinoamericanos y de España. Si bien se trata de preparaciones muy distintas, suelen tener en común el hecho de ser alimentos semilíquidos de consistencia espesa. En Argentina, la mazamorra es un postre tradicional de raíces indígenas elaborado con maíz blanco, agua, azúcar y vainilla. La variante más consumida es la mazamorra con leche, añadida en abundancia a los ingredientes anteriores. Es típico consumir mazamorra en las fiestas nacionales y en los actos realizados en las escuelas argentinas por el 25 de mayo no falta el personaje prototípico afroargentino de «la negra mazamorrera», vendedora de ese dulce en época virreinal.

10 Lucio Victorio Mansilla (Buenos Aires 1831-París 1913), hijo de un militar y héroe del conflicto en contra del bloqueo anglo-francés y de la hermana menor del dictador Juan Manuel de Rosas. Fue una personalidad multifacética que se desempeñó en diferentes actividades: general de división del Ejército Argentino (combatió en la guerra de Paraguay), periodista, escritor, político y diplomático, gobernador del Territorio Nacional del Gran Chaco entre 1878 y 1879. Viajó desde muy joven a Asia, África y Europa donde se radicó -entre Francia e Inglaterra- en los años de su madurez.

11 Escrito en París cuando su autor tenía más de setenta años de edad, en palabras de Ghiano $(1955,31)$ pertenece a las obras que «Rojas ha destacado [como] publicaciones [que] comentan el desarrollo cronológico de la existencia de Mansilla: Mis memorias corresponden a la infancia y la adolescencia; De Adén a Suez y Recuerdos de Egipto, sintetizan andanzas juveniles: Retratos y recuerdos, los años pasados en la Capital de la Confederación y en Santa Fe, durante el obligatorio destierro; Una excursión a los indios ranqueles contiene valiosas referencias de los años maduros; los tomos de las Causeries acumulan anécdotas de toda su existencia». 
se refiere a los años de la infancia y adolescencia, como especifica el subtítulo, y privilegia los sentimientos y el punto de vista del niño. El autor reconstruye el Buenos Aires de aquellos tiempos basándose en los recuerdos de sus primeros años. De hecho recrea el espacio y la red de relaciones familiares y amicales diseñando y re-andando los itinerarios del niño Mansilla -empezando por su manzana y barrio hasta llegar a la ciudad y sus alrededores-; acompaña al lector por las casas frecuentadas antaño a través de un entramado de descripciones que hacen hincapié en la arquitectura, el mobiliario, la vestimenta, los acontecimientos políticos de la época junto a las consideraciones literarias y filosóficas del Mansilla adulto, sin olvidar las tradiciones alimentares. Este intento de recuperar el punto de vista infantil le da al texto un carácter íntimo, nostálgico y memorioso que bien se resume en el epígrafe: «ACORDARSE ES REVIVIR...» (Mansilla 1955: 59). Huelga decir que el ámbito elegido es muy acotado, como afirma Juan Carlos Ghiano (1955: 54) en su estudio preliminar, la "prosa vivaz, muy pocas veces desvaída [...] se va internando [...] en la ciudad todavía externamente colonial; [...] [y muestra] así las costumbres del patriciado argentino, la dignidad de algunos inmigrantes excelentes, el respeto y la discreción con que se vivía en la verdadera "gran aldea"».

Es posiblemente la fuerte participación emocional más que la pertenencia a una elevada y refinada capa social -muy parecida, si no idéntica en ambos autores- la que lleva a Mansilla a ofrecer una evaluación de la alimentación en la sociedad porteña opuesta a la propuesta por Wilde:

Hay gente que cree que, en la época de que hablamos, no se comía bien.

Es preciso que salgan de su error (Mansilla 1955: 208).

Lo mismo afirma de la etiqueta y los servicios de mesa:

lo que yo puedo asegurar, lo repito todavía, es que esas mesas, entre las que incluyo como copiosa, patriarcal la de los Llavallol, [...], no le iban en zaga a las mejores de los tiempos que alcanzamos. Y la del señor don Miguel Riglos con su cristalería, su porcelana, sus cubiertos, sus manteles, todo inglés del mejor gusto, de lo más fino (Mansilla 1955: 210).

Los alimentos y menús mencionados por Mansilla en las Memorias conforman una variada lista, propongo aquí la más tradicional:

Pero como lo prometido es deuda, vengamos a lo que se podía comer antes de la irrupción internacional: carne de vaca, de chancho, de carnero, lechones, corderitos, conejos, mulitas y peludos; carne con cuero y matahambre arrollado; gallinas y pollos, patos caseros y silvestres, gansos, gallinetas y pavas, perdices, chorlitos y becasinas, pichones de lechuza y de loro (bocado de cardenal); huevos de gallina naturalmente y los finísimos de perdiz y teruteru; pescados desde el pacú, que ya no se ve, hasta el pejerrey, y del sábalo no hay que hablar; porotos, habas, maní, fariña, fideos, sémola, arvejas, chauchas, garbanzos, lentejas, espinajas, coles, nabos, zanahorias, papas, zapallos, berenjenas, alcauciles, pepinos, tomates, cebollas, pimientos, lechugas varias (zzapallitos tiernos para el Carnaval! gritaban los vendedores), quesillos y quesos, siendo los más reputados los de Goya y Tafí, y los de Holanda, genuinos entonces; 
frutas de no pocas clases, higos, uvas, guindas, frutillas, damascos, peras, pelones, melones, sandías, ciruelas, nísperos, naranjas, bananas (escasas). Cuando caía granizo en abundancia se recogía una buena cantidad, y se hacían helados de leche y huevo con canela o con vainilla. Todos movíamos el cilindro por turno.

Agréguese a esto las conservas alimenticias y todo lo que se me haya quedado en el tintero, y concluyendo con las pasas, los orejones, las nueces, las avellanas y la pastelería de choclo y harina y los dulces, se verá si dije o no mal cuando aseguré que nuestros abuelos, siendo frugales, comían bien y de lo aconsejado por la moderna higiene (Mansilla, 1955: 211).

Wilde y Mansilla coinciden en poner en evidencia la frugalidad de antaño y proponen una lista muy similar de alimentos habitualmente consumidos con sus respectivas elaboraciones. Sin embargo, hemos apreciado que, a pesar del parecido de los elementos considerados, evalúan los tiempos pasados y sus costumbres de forma opuesta.

\section{Representación de los alimentos del interior o de Tierra Adentro}

Diferentemente a lo que se nota en las memorias porteñas de Wilde y Mansilla, en la galería de retratos provincianos de los Recuerdos de Sarmiento ${ }^{12}$ escasean las referencias a la comida, incluso, en un caso ejemplar, esta es presentada en forma antagónica a los libros:

Allí estaba la historia antigua, i aquella Persia, i aquel Ejipto, i aquellas Pirámides, i aquel Nilo de que me hablaba el clérigo Oro. La historia de Grecia la estudié de memoria, i la de Roma en seguida, sintiéndome sucesivamente Leonidas i Bruto, Arístides, i Camilo, Harmodio, i Epaminondas; i esto mientras vendia yerba i azúcar, i ponía mala cara a los que me venian a sacar de aquel mundo que yo habia descubierto para vivir en él (Sarmiento 1850: 145). ${ }^{13}$

El autor estructura el párrafo como si, presionado por el deseo de afirmar al mismo tiempo su honda formación cultural y el esfuerzo de autodidacta con el que la ha conquistado, considerara necesario contraponer alimento del cuerpo y del espíritu, privilegiando incuestionablemente el segundo. Los escasos ejemplos de "alimento del cuerpo" presentes en la obra se refieren a huevos de avestruz (38), ${ }^{14}$ queso (38), charqui $(183),{ }^{15}$ legumbres $(50,119)$, puchero (120), fruta (116,

12Domingo Faustino Sarmiento (San Juan, 1811 - Asunción del Paraguay, 1888) fue político, escritor, docente, periodista y militar argentino; Gobernador de la Provincia de San Juan entre 1862 y 1864, Presidente de la Nación entre 1868 y 1874, Senador Nacional por su Provincia entre 1874 y 1879 y Ministro del Interior de Argentina en 1879. Se lo recuerda principalmente como el principal impulsor del sistema educativo nacional: multiplicó el número de alumnos en las escuelas, creó la primera institución dedicada a la formación de maestros, impulsó la creación de escuelas en todas las geografías de la nación. Fue autor de una copiosa producción periodística, pedagógica, ensayistica y literaria.

13 Mantengo la grafía original. La lectura como forma de inclusión autorizada en lo nacional es otro rasgo muy presente en Sarmiento, al respecto escribe Molloy (1988: 413) «Hay alarde de lectura en Sarmiento, necesidad de volver constantemente a esa actividad que lo signa. Manía de autodidacta [...] de rebelde que desafía a la academia con su personalísima máquina de aprender, reivindicando un cuerpo a cuerpo con el libro en el que sobran los mediadores».

14Cito por la edición consignada en bibliografía indicando en paréntesis las páginas.

15Elaboración típica del subcontinente americano, el charqui -cuyo nombre procede del quechua- es carne deshidratada, salada y secada al aire o al sol para que se conserve. 
118), yerba y azúcar (183) y, hablando de los pueblos originarios del área, a las vicuñas (10). De hecho, aun mencionando algunos alimentos ya presentados por Wilde y Mansilla, en las páginas de Sarmiento se encuentran otros poco usuales para un comensal europeo. Cabe interpretar el "silencio alimentario" del sanjuanino no solamente como indicio de la predilección por temáticas que se apartan de la vida cotidiana, poco frecuentada en su escritura, sino también como rechazo de una materia que -en su versión provincial- resultaba tal vez demasiado bárbara y cercana a la tradición gaucha y autóctona para el teórico de la civilización al estilo europeo, mientras que el alarde cosmopolita -más que europeizante- de los autores capitalinos les permitiría más soltura a la hora de hacer hincapié en las costumbres locales. ${ }^{16}$

Por otra parte en el primer capítulo de la más conocida entre las obras de Sarmiento, Facundo. Civilización y barbarie (1845), encontramos dos escenas relacionadas con la comida (y la barbarie). En la primera, la tripulación de una solitaria caravana de carretas reunida alrededor del fogón, tras cerciorarse de que ningún peligro esté al asecho, «continua la conversación interrumpida o lleva a la boca el tasajo de carne medio sollamado de que se alimenta» (Sarmiento 2018: 50). Sucesivamente, a la hora de describir la «educación del hombre de campo» y demonstrar -por la errónea formación que recibe y la falta de toda participación a la vida social- la inadecuación del gaucho al progreso, aclara que «Las mujeres guardan la casa, preparen la comida, trasquilan las ovejas, ordeñan las vacas, fabrican los quesos» (Sarmiento 2018: 62). La primera escena enfatiza la costumbre a la comida carnea ${ }^{17}$ que identifica metonímicamente el asado con la alimentación nacional o con la Argentina tout-court ${ }^{18}$ además de hacer hincapié en su consumición poco menos que primitiva ya que es casi cruda. La segunda escena nos presenta un cuadro socio-económico pastoril, atrasado, casi medioeval, usando el término en el sentido peyorativo atribuido a dicho período histórico.

16 Sin embargo cabe recordar que en otros textos Sarmiento recupera varios aspectos de las culturas locales como indica Matías Bruera: «En su texto sobre Muñiz, rescata lo autóctono -desde la invención hecha por nuestros antecesores históricos de las boleadoras hasta la cría y el consumo de ñandúes, avestruces, mulitas, carpinchos y osos lavanderos"anunciando la fauna de la pampa al mundo gastrónomo del siglo veinte"» (Bruera 2006: 63). El mismo Bruera (2006: 64) refiere una anécdota preciosa que revela la intención de Sarmiento de mofarse del adoctrinamiento culinario francés propio de la aristocracia local que despreciaba lo criollo por bárbaro. En su residencia del Tigre, después de una exquisita comida, Sarmiento aclaró a sus huéspedes que les había servido carpincho por liebre y así lo cuenta él mismo: «La carne es excelente, y en una fiesta veneciana tenida en el Carapachay todo el High Life gustó en general de un enorme carpincho asado, chupándose los dedos las damas que no sabían que era carpincho, y relamiéndose los bigotes los machos que lo sabían» (Sarmiento 1948).

17 Como es sabido, la Argentina se caracteriza por la difusa tradición culinaria del asado, uso que, de forma paradigmática se reverbera en la conocida representación del pasto antropófago propuesta por Juan José Saer en El entenado (cf. Salvioni 2010).

18Se mueve en este sentido la intención manifestada por algunos políticos argentinos -la Diputada Sandra Paris de la Provincia de Buenos Aires y el Diputado Alberto Asseff de la Nación- de llegar al reconocimiento de la condición de patrimonio cultural al asado de tira (https://prisioneroenargentina.com/index.php/2020/11/10/es-el-asadode-tira-patrimonio-cultural-de-los-argentinos-o-de-la-humanidad/). El renombre de esa comida suele facilitar una identificación privilegiada con la nación que borra las demás tradiciones del país, mecanismo que se vio incrementado en los casos en los que algunos alimentos lograron el reconocimiento del estatuto de patrimonio inmaterial de la humanidad por parte de la Unesco (Cf. Di Fiore 2021). 
Los detalles mencionados nos recuerdan que en todo contexto la alimentación, mejor dicho, la gastronomía presenta un acusado valor cultural y brinda un privilegiado espacio epistemológico. Resulta elocuente al respecto el caso de Una excursión a los indios ranqueles ${ }^{19}$ de Mansilla, universo dialógico donde se relacionan los opuestos antropológicos y culturales de la Argentina decimonónica -blancos-militares e indios o, acudiendo al binomio sarmientino, civilización y barbarie-. Amanda Salvioni subraya «la frecuencia y la centralidad de las escenas conviviales» en el texto $(2016,18)$ y, a partir de dicho aspecto, la temática del conocimiento del "Otro" que atraviesa la narración y se expresa a través de una semántica de la comida. "Otro" pampeano, en el caso de la Excursión, cuya cultura por momentos se ve evaluada como una de las muchas conocidas por Mansilla a lo largo de sus viajes, quién no duda en hacerlo manifiesto en el conocido íncipit dirigido a Santiago Arcos, el amigo y destinatario interno de la relación:

\begin{abstract}
después de haber recorrido la Europa y la América, de haber vivido como un marqués en París y como un guaraní en el Paraguay; de haber comido mazamorra en el Río de la Plata, charquicán en Chile, ostras en Nueva York, macarroni en Nápoles, trufas en el Périgord, chipá en la Asunción, recuerdo que una de las grandes aspiraciones de tu vida era comer una tortilla de huevos de aquella ave pampeana en Nagüel Mapo, que quiere decir «Lugar del Tigre» (Mansilla 1984: 3, cursiva del autor).
\end{abstract}

Las descripciones de escenas conviviales se detienen en las sencillas preparaciones de la gastronomía pampeana y: «Lo primero que salta a la vista es que asados y pucheros son las dos formas elementales y universales de la práctica culinaria» (Salvioni 2016: 20). Práctica universal porque involucra por igual a blancos e indios hasta aconsejar la siguiente lectura: «Asados y pucheros parecen ser letras de un alfabeto primordial con el que los habitantes del desierto argentino traducen su propia estructura social, poniendo de manifiesto su situación liminar, es decir su condición de residentes en la frontera entre la naturaleza y la cultura» (Salvioni 2016: 20).

\title{
Comparando tradiciones
}

El uso indiferenciado y general de las dos prácticas culinarias resulta tanto más sorprendente cuando se piensa en las lecturas que los estudios etnográficos e históricos proponen del binomio

19 Una excursión a los indios ranqueles es la obra literaria más conocida de Mansilla. Fue publicada como apostillas en el diario La Tribuna a partir del 20 de mayo de 1870. El director del diario La Tribuna recopiló las cartas publicadas más otras cuatro finales, que nunca se publicaron en el diario y con todo ese material se completó, ese mismo año, la primera edición del libro completo, en Buenos Aires. En 1875 recibió el primer premio en el Congreso Geográfico Internacional de París. Se tradujo con el tiempo a varios idiomas. El libro es fruto de una recorrida que el autor emprendió en 1870 por las regiones de los pueblos originarios desde el fuerte cordobés Sarmiento de Río Cuarto hasta la laguna Leuvucó en los actuales límites de la provincias de La Pampa y San Luis. En este último lugar Mansilla se encontró con el cacique Mariano Rosas e intentó convencerlo de refrendar un tratado de paz que en verdad él sabía que tendría una validez relativa, ya que si bien Sarmiento lo había aprobado como Presidente, aún faltaba el voto favorable del Congreso.

SCRIPTA, Revista internacional de literatura i cultura medieval i moderna, núm. 18 / desembre 2021 / pp. 167-181 ISSN: $2340-4841 \cdot$ doi:10.7203/SCRIPTA.18.22772 
o, mejor dicho, la antinomia asado-hervido. Claude Levi Strauss (2003) pone en los extremos de su conocido triángulo culinario las categorías de crudo, cocido y podrido acercando la primera a la preparación arquetípica de lo asado y la segunda a la de lo hervido, dos formas de cocción que se ponen en la frontera entre lo natural y lo cultural, las atribuciones de género, la definición del destinatario y la estructura social del grupo. En la exposición directa a la llama que se usa en el asado se eliminarían las intermediaciones culturales propias de una sociedad más evolucionada, mientras que su elaboración se connotaría por un rasgo varonil frente a la preparación de los alimentos hervidos, contenidos en ollas y normalmente a cargo de las mujeres; finalmente el antropólogo subraya la diferencia entre la exococina -preparación hecha al aire libre para un grupo que excede el núcleo familiar-como es el asado, y la endococina -elaboración «hecha para el uso íntimo y destinada a un número reducido y cerrado» (Lévi Strauss 2003: 421)- como en el caso del puchero. De aquí la creación de una frontera prototípica entre culturas.

De un punto de vista histórico, Massimo Montanari (1993: 12-23) ve en la oposición asado-hervido el deslinde entre la alimentación de la cultura romana de época clásica y la gastronomía medioeval germánica, un paso de la cultura del ager-el campo cultivado latino- a la del saltus -el bosque que en la Edad Media posibilita la actividad de la caza y provee leña. La primera es caracterizada por el cultivo y el uso de cereales y legumbres elaborados en sopa y puls (Montanari 2009: 21), propia de sociedades marcadas por la parquedad de poblaciones agrícolas y sedentarias; la segunda típica de poblaciones cazadoras, a menudo nómadas y guerreras que veían en la ingesta de carne y materias grasas no solamente la respuesta a un gusto compartido sino una afirmación de fuerza y poder de parte del comensal-cazador. Dos paradigmas alternativos que se han complementado en los largos años de la Edad Media hasta forjar la tradición europea.

Como se ha podido ver, el paradigma interpretativo histórico se refleja en la lectura antropológica que así se resume en las palabras de Lévi Strauss (2003: 427): «situada así entre la naturaleza y la cultura, la cocina garantiza más bien su necesaria articulación. Participa de ambos dominios y refleja esta dualidad en cada una de sus manifestaciones». Para mejor apreciar el valor epistémico de la cocina en el contexto considerado, cabe hacer hincapié por un lado en el uso común entre pueblos originarios y descendientes de europeos (militares-diplomáticos-civilizadores)- de lo asado y lo hervido relevado por Mansilla en la Excursión; por otro lado recordar que una análoga conmistión se puede observar en los menús ilustrados por Wilde y Mansillas. A lo dicho hay que añadir una difusa propensión, incluso en el "civil" Buenos Aires, por alimentos muy americanos - ¿barbaros, tal vez? - desde la vicuña mentada por Sarmiento a las variedades carneas disponibles en los mercados porteños y nombradas por Wilde -«La carne se vendía donde hoy es el Congreso, las perdices y mulitas (de las que entonces se traían muchas)»,(2000: 29)-; hasta la amplia lista de mulitas y peludos, ${ }^{20}$ pichones de lechuza y de loro; huevos de perdiz y teruteru ${ }^{21}$ mencionada por

20 Peludo y mulita son voces rioplatenses para definir dos variedades de armadillos.

21 Ave zancuda, de la misma familia que los andarríos, de 30 a $40 \mathrm{~cm}$ de envergadura, con plumaje de color blanco con mezcla de negro y pardo, típica del subcontinente americano. 
Mansilla (1955: 211), sin dejar de lado el conocido charqui. Nos encontramos entonces frente a un panorama de tradiciones alimentarias con muchos puntos comunes entre pueblos originarios y europeos por elaboración culinaria y selección de alimentos que, incluso en las zonas urbanas, se ven hibridados con los criollos definiendo un abanico de gustos compartidos. En este marco, la anterior consideración del etnólogo francés pone de manifiesto la contradictoria mirada puesta en el indio -la expresión de la naturaleza salvaje en la visión civilizada y europeizante- cuya evaluación no se sustenta en una verdad ontológica e incuestionable sino en un cambiante prejuicio social. Si ingredientes y preparaciones culinarias son comunes entre los descendientes de europeos y los pueblos originarios cabe pensar con Flandrin que la verdadera explicación reside en la llamada estructura del gusto (que en su ensayo el estudioso analiza centrándose en el uso de las materias grasas en Francia): «D’abord que la quantité de graisse utilisée en cuisine ne dépend pas seulement des disponibilités et des besoins physiologiques liés au sol et au climat, mais aussi des tendances du goût» (Flandrin 1983: 390-391). En el caso que nos ocupa las poblaciones europeas y originarias muestran compartir la misma estructura del gusto que los lleva a seleccionar alimentos comunes y elaborarlos de forma análoga, poniendo en tela de juicio la supuesta superioridad cultural de un componente demográfico frente al otro.

Pero ¿qué autoriza, entonces, la inclusión en el universo civilizado de los unos y el estigma de la pertenencia a la naturaleza bárbara en el caso de los otros sino el prejuicio, una mirada viciada y un interés económico?

\section{Pocas consideraciones sobre los usos léxicos}

Antes de esbozar algunas consideraciones sobre las elecciones léxicas de nuestros autores en el campo semántico de la gastronomía, cabe recordar que los escritores examinados son intelectuales poliglotas y cosmopolitas que usan con frecuencia en sus textos múltiples calcos y, particularmente, préstamos procedentes de diferentes lenguas, en ámbito culinario como en todo sector. Sin embargo no quiero centrar estas pocas líneas en los extranjerismos presente,s así como quiero mentar solo de paso que, al limitarse los textos a los años anteriores a las grandes oleadas migratorias, no se encuentran allí las ricas marcas que la cultura de los recién llegados dejaría en la variante argentina del castellano hasta el día de hoy. ${ }^{22}$ Deseo en cambio observar que en el léxico de la alimentación usado por los autores encontramos tres categorías de palabras. Por un lado los términos patrimoniales americanos, préstamos procedentes del substrato autóctono como: «chicha», «charqui», «mulita», «peludo».

Secundariamente, significantes distintos que definen idénticas preparaciones presentes en el área rioplatense y en la península ibérica. Es el caso de «puchero», equivalente del peninsular «cocido». El DRAE en su segunda entrada aclara: «2. m. Especie de cocido, como el cocido español».

Así como variantes rioplatenses que definen verduras y otros alimentos: «chauchas», «zapallitos»,

22 Relativamente a la influencia italiana véase Fontanella de Weinberg (1994, 2000), Di Tullio (2002, 2003, 2012). 
«papa», «poroto», «mondongo» sin que se mencionen nunca los correspondientes peninsulares, respectivamente: «judías verdes», «calabacines», «patata», «judía», «callos».

Finalmente expresiones de carácter descriptivo-metafóricos que designan preparaciones comunes a ambos contextos geográfico-culturales, como los «niños envueltos»; o bien, y me parece el caso culturalmente más elocuente, comidas similares elaboradas con ingredientes que remiten a una distinta planta de civilización, como las definió Fernand Braudel. Resulta ejemplar el caso de la «mazamorra» americana hecha con maíz, la planta cultural típica del área amerindia, muy similar a la «natilla», presente en Argentina como en España, elaborada a base de arroz, planta de civilización característica del oriente pero felizmente asentada también en Europa.

De este veloz recorrido se puede notar que la lengua declara una americanidad que excede los posicionamientos ideológicos de la época y contradice la reivindicada atención puesta en una Europa inspiradora.

\section{Conclusiones}

Las consideraciones de estas páginas espero hayan podido subrayar la valencia epistémica de la gastronomía y, relativamente al período histórico y al área geográfica elegidos, resaltado una conformidad de las prácticas culinarias que entretejen inesperados contactos entre mundos -el blanco y el indio- considerados antitéticos e irreconciliables. Una conformidad que no valdrá la salvación del universo de los pobladores originarios, como sabemos, sino que indica una cercanía cultural que la ideología positivista de la época no quiso ver ni admitir. El lenguaje de las obras consideradas, en cambio, resulta un inesperado indicador no solo de una enraizada identidad americana de marca criolla sino de una sorprendente capacidad de inclusión, en lo puramente léxico, de las culturas originarias. 
Ilaria Mangani. La identidad en el plato. El camino identitario argentino a través de sus alimentos

\section{Bibliografia}

Bruera, M. (2006) La Argentina fermentada. Vino, alimentación y cultura, Buenos Aires, Editorial Paidós.

Campanini, A. (2021) «I banchetti come rituale politico (secolo XV e XVI)», en Montanari M. (ed.) Cucina politica: Il linguaggio del cibo fra pratiche sociali e rappresentazioni ideologiche, Bari, Laterza, pp. $42-54$.

Di Fiore, L. (2021) «Cibo e patrimonio, una questione política», en Montanari, M. (ed.) Cucina politica: Il linguaggio del cibo fra pratiche sociali e rappresentazioni ideologiche, Bari, Laterza, pp. 185-198.

Di Tullio, Á. (2002) «La lingua dell'immigrante: tra realtà e fantasia», en Atti della II settimana della lingua italiana nel mondo, 14-19 ottobre 2002, Buenos Aires, Istituto Italiano di Cultura, Ministero degli Affari Esteri, Accademia della Crusca, Ministero per gli Italiani all'Estero.

Di Tullio, Á. (2003) Políticas lingüisticas e inmigración, Buenos Aires, Eudeba.

Di Tullio, Á. (2012) «Lingua», en Patat, A. y Di Tullio, Á., «Argentina», en Patat, A. (ed.)Vida nueva. La lingua e la cultura italiana in America Latina, Macerata, Quodlibet, pp. 38-63.

Flandrin, J.-L. (1983) «Le goût et la nécessité: sur l'usage des graisses: Dans les cuisines d'Europe occidentale (XIVe- XVIIIe siècle)», Annales. Histoire, Sciences Sociales, 38e Année, No. 2, pp. 369- 401.

Fontanella de Weinberg, M.B. (1994) “"Una fugaza con fetas de panceta y provolone”: la incorporación léxica en español bonaerense», Estudios sobre el español de Argentina III, Bahía Blanca, Departamento de Humanidades, Universidad Nacional del Sur.

Fontanella de Weinberg, M.B. (2000) «El español bonaerense», en Fontanella de Weinberg, M.B. (ed.) El español de la Argentina y sus variedades regionales, Buenos Aires, Edical, pp. 37-61.

Ghiano, J.C. (1955) Estudio preliminar, en Lucio Victorio Mansilla, Mis recuerdos. Infancia-Adolescencia, Buenos Aires, Hachette, pp. 7-55. Edición digital Alicante, Biblioteca Virtual Miguel de Cervantes, 2001, http://www.cervantesvirtual.com/obra/mis-memorias-infancia-adolescencia/.

Lévi Strauss, C. (2003 [1968]) «Breve tratado de etnología culinaria», en El origen de las maneras de mesa. Mitologías III., México D.F.-Buenos Aires, Siglo XXI, pp. 410-432.

Mansilla, L.V. (1984 [1870]) Una excursión a los indios ranqueles, edición, prólogo y cronología de Sosnowski S., Caracas, Fundación Biblioteca de Ayacucho.

Mansilla, L.V. (1955) Mis recuerdos. Infancia-Adolescencia, Buenos Aires, Hachette, Edición digital Alicante, Biblioteca Virtual Miguel de Cervantes, 2001, http://www.cervantesvirtual.com/ obra/mis-memorias-infancia-adolescencia/.

Molloy, S. (1988) «Sarmiento, lector de sí mismo en Recuerdos de provincia», Revista Iberoamericana, Vol. LIV, Núm. 143, pp. 407-418.

Montanari, M. (1993) La fame e l'abbondanza. Storia dell'alimentazione in Europa, Bari, Laterza. 
Ilaria Mangani. La identidad en el plato. El camino identitario argentino a través de sus alimentos

Montanari, M. (2006) Il cibo come cultura, Bari, Laterza.

Montanari, M. (2009) Il riposo della polpetta e altre storie intorno al cibo, Bari, Laterza.

Montanari, M. (2021) «Il linguaggio del cibo» en Montanari, M. (ed.), Cucina politica: Il linguaggio del cibo fra pratiche sociali e rappresentazioni ideologiche, Bari, Laterza, pp. 12-13.

Salvioni, A. (2010) «Una poetica della convivialità: l'asado come leitmotiv nella narrativa di Juan José Saer», Oltreoceano, 4, pp. 275-285.

Salvioni, A. (2016) «Gastronomía de la pampa. (La escena convivial en Una excursión a los indios ranqueles)», Letterature d'America, Anno XXXVI, n. 158, 2016, pp. 5-31.

Sarmiento, D.F. (1850) Recuerdos de provincia, Santiago, Imprenta de Julio Belin i Compañía, disponible en http://www.memoriachilena.gob.cl/602/w3-article-165720.html.

Sarmiento, D.F. (1948) Obras Completas, Tomo XLIII, «Francisco J. Muñiz», Buenos Aires, Ediciones Culturales Argentinas, p. 99.

Sarmiento, D.F. (2018 [1845]) Facundo, o, Civilización y barbarie, prólogo de Laera, A., Buenos Aires, Biblioteca del Congreso de la Nación, disponible en https://bcn.gob.ar/uploads/Facundo_ Sarmiento.pdf.

Valerio, C. «¿Es el asado de tira patrimonio cultural de los argentinos; o de la humanidad?» en Prisionero en Argentina, https:/ / prisioneroenargentina.com/index.php/2020/11/10/es-el-asadode-tira-patrimonio-cultural-de-los-argentinos-o-de-la-humanidad.

Wilde, J.A. (2000 [1881]) Buenos Aires desde setenta años atrás (1810-1880), s.l., Ediciones elaleph.com, 2000. 